Journal of Economics and Behavioral Studies (ISSN: 2220-6140)

Vol. 7, No. 6, pp. 94-110, December 2015

\title{
Does Culture Matter to Pro-Social Behavior? Evidence from a Cross-Ethnic Lab Experiment
}

\author{
Fengwei Sun, ${ }^{*}$ Xunzhou Ma, Xiaoxiao Wang, Quanlan Yi, Mengliang Wu \\ College of Economics, Southwest University for Nationalities, China \\ *pooreco@163.com
}

\begin{abstract}
Recent investigations have uncovered large, consistent deviations from the predictions of Homo economics that individuals are entirely self-regarding. Our study undertook a cross-cultural study of behavior search for the evidences of other-regarding behaviors and its ethnic difference, and accounted for by anatomy of culture. This study recruited 90 subjects of three ethnic groups from market trade-based (ethnic Han), nomadism-based (ethnic Zang) and agriculture-based (ethnic Bouyei) areas in China and conducted public good provision experiment with stranger-treatment design. Under the assumption of self-regarding preferences, the Nash equilibrium is zero contribution by all in public account using backward induction. However, we found contributions did not reduce to zero over all three sessions. Besides, the differences in contributions between ethnicities strongly depended on the degree of ethnic dominance, and Zang harbored the strongest reciprocal preference generally over all group structures. A particular set of measurable factors was identified as proxies for cultural influences on behavioral differences observed in experiments between ethnicities. The results showed all of the cultural factors accounted for the behavioral differences between the ethnic Han and the other two minor ethnicities. However, behavioral difference between minor ethnicities was attributed to group structure only. (1) People may harbor various forms of prosocial emotions in economic affairs, and especially exhibit stronger at the initial phase rather than what canonical model assumes. (2) Behavioral differences between ethnicities are prominent and can be explained by differences in cultural influence.
\end{abstract}

Keywords: Prosocial behavior, Public good provision game, Culture, Ethnicity, Group structure

\section{Introduction}

A number of recent contributions have shown the consistent deviations from the predictions of orthodox economics of Homo economics by detecting the other-regarding behaviors, i.e., prosocial behavior, in economic affairs (Andreoni, 1990; Camerer, 1997; Henrich, 2000; Glaeser et al., 2000). According to cultural psychological theories, fundamental differences in how culture affects people's perception of the world might predict differences in how people make economic decisions (Miller, 1984; Shweder, 1990; Triandis, 1995). In recent years, much experimental work has focused on cultural effects on prosocial behaviors (e.g., Burlando and Hey, 1997; Ockenfels and Weimann, 1999; Henrich, 2000; Glaeser et al., 2000; Fershtman, Gneezy, 2014; Castro, 2008). However, these studies merely report the differences in prosocial behavior between ethnic groups and naturally attribute the effects culture has on behavior to the individual level. Culture is difficult to univocally define, although most commonly this term is used for tribes or ethnic groups (in anthropology) or for nations (in political science, sociology and management) (Hofstede, 2011). Until recently, economists have been reluctant to rely on culture as a possible determinant of economic phenomena. Much of this reluctance stems from the very notion of culture: it is so broad and the channels through which it can enter the economic discourse is so ubiquitous (and vague) that it is difficult to design testable (i.e., refutable) hypotheses (Guiso et al., 2006). A very small amount of research has conducted analysis of the economic anatomy of culture. The work of Chuah, Hoffmann and Williams (2009) examines bargaining behavior in an experimental ultimatum game with Malaysian and UK subjects and assesses to what extent attitudes in terms of culture may be responsible for the prosocial behavioral differences using a number of comprehensive attitudinal surveys of individuals sourced from the fourth wave (1999-2000) of the World Values Survey (WVS, see Inglehart, 1997). Other research has mainly focused on the effects of religions (Sosis and Ruffle, 2004; Benjamin et al., 2013). 
In this study, we defined culture in a sufficiently narrow manner (i.e., the culture of a particular people is a shared set of beliefs, values, conventions, ethnic affiliations and way of economic life) to make it easier to identify the causal links from culture to prosocial behavior. This study proceeded as follows: (1) We framed the standard linear public good provision games and conducted three treatments based on the games by manipulating the ethnic composition of the experimental groups, and then, detected the prosocial behavioral differences between ethnicities. (2) We next assess whether, and if so, in what ways, our subjects' different cultural backgrounds generated any observed behavioral differences between ethnicities. Based on our definition of culture, we collected a number of survey questions, including questions sourced from $W V S$ and regarding family status information, to combine with our own questions (Prosocial Preference Survey, PPS. See Table 7). All the questions were grouped into five independent sections that can provide measurements of dimensions of culture in terms of prosocial preferences ${ }^{1}$ : people's attitudes toward participation, out-group rejection (desirability as neighbors), religion, market interaction, and centralization of power of a family. After the completion of the experimental game, we distributed the questionnaire to collect the survey data from every subject during an interval of 30 to $40 \mathrm{~min}$. Then, we assess whether the differences in various corresponding dimensions of culture exist between ethnicity. This study is intended to account for the ethnic behavioral difference by more enriched anatomy of culture (including both potential cultural dimensionsattitude and objective way of economic life- according to the results of related studies) in order to reveal the pattern of cultural influence on the ethnic behavioral difference more completely. This paper is structured as follows: Section 2 introduces our experimental design. Section 3 first provides the results of investigations into behavioral differences in public good provision games and then identifies to what extent dimensions of culture may be responsible for the behavioral differences in contributions observed in experiments associated with different ethnicities. Finally, we present the conclusions and discussion in Section 4.

\section{Experimental Design}

The experiment was conducted at the Southwest University for Nationalities, China. A total of 90 subjects were equally divided between three ethnicities. Our sampling has the following considerations. First, we selected subjects from the ethnic Han group, which is the majority, and from two ethnic minority groups, the ethnic Zang, which is the largest minority group, and the ethnic Bouyei, which is a relatively small minority group in China, to make a greater variation in ethnic population scales ${ }^{2}$. Second, these ethnicities exhibit different economic conditions. The ethnic Zang and Bouyei practice nomadism and agriculture respectively, while the ethnic Han live in a commercial economic society. Third, the participants are almost entirely freshmen who have entered into college for less than three months and grew up in the original regions of the ethnicities ${ }^{3}$. This is expected to reduce the influences from other cultures and customs. Fourth, our recruitment proceeded in the following manner: after obtaining the subject's file from the dean's office, we contacted their counselors to inform the subjects to take part in the experiment rather than put up advertisements, which would likely have induced sample selection bias; i.e., those who came to the game could have had stronger cooperative tendencies. Additionally, we recruited from a wide range of fields such as Economics, Ethnology, Sociology, Chemistry, Biology, Psychology, Physics, Linguistics and Business.

The whole experiment was divided into two phases with 45 participants in each phase. In the first phase, we conducted 3 consecutive treatment sessions, each composed of 10 decision-making rounds. In other words, participants played 30 rounds of public good provision games in total. In the first treatment session, all the subjects were randomly divided into 9 groups, and every group had 5 subjects who were aware that they played in a group comprised of different ethnicities (labeled 'diverse group'). In the second treatment session, the subjects were randomly divided within a sample of their own ethnicity (labeled 'homogeneous group'). In the third treatment session, we firstly randomly selected 9 subjects equally from three ethnicities and then matched every subject with 4 other subjects different from his/her ethnic affiliation from the rest of the

\footnotetext{
${ }^{1}$ WVS includes a broad scope and wide-ranging poll of socio-economic and political values and consists of more than 200 individual questions.

${ }^{2}$ The population proportion in China of Han, Zang and Bouyei are $91.6 \%, 0.47 \%$ and $0.22 \%$, respectively (National Bureau of Statistics of China. China Statistical Yearbook. http://www.stats.gov.cn/tjsj/pcsj/rkpc/6rp/indexch.htm).

${ }^{3}$ Five participants quit the experiment for personal emergencies and another five subjects who shared their same ethnicities, but study in higher grade were instead.
} 
subjects (labeled 'one ethnicity dominant group'). To avoid the order effect, in the second phase, we conducted the treatment sessions in the following order: the 'homogeneous group,' the 'one ethnicity dominant group' and then the 'diverse group'. Most experiments usually provide predictions of behavior by playing repeated games with subjects as many one-shot games. However, the results from Botelho, Harrison, Pinto Costa and Rutström (2009) argue that there is some chance that subjects will meet in multiple rounds, and the assumption that subjects treat random strangers designs as if they were one-shot experiments is false; thus, a reputation effect may develop. Therefore, the group structures were public information over all sessions, although the subjects were not allowed to obtain the information on recruitment numbers of any ethnicity and types of ethnicities to make them feel there was no chance that they would meet the same person in any other round to rule out reputation effects as well as effects of ethnic stereotype, and thus develop an instinct towards prosocial behavior (Fershtman and Gneezy, 2014).

All sessions used the standard linear public good provision game including both neutrally worded and written instructions (See Appendix B). Five subjects in a group were endowed with 50 tokens each at the beginning of each round and each token was converted into money using an exchange rate of 1RMB $(0.16 \text { US } \$)^{4}$ at the end of the experiment. They decided on the allocation of their endowment between a private and public good. Each token held in private earned one token for the participant only whereas each token placed in the public good earned 0.5 times the token for each member of group. Let $g_{i}\left(0 \leq g_{i} \leq 50\right)$

be the subject $i$ ' contribution to the group account and let $\pi_{i}$ be the payoff given by

$$
\pi_{i}=50-g_{i}+0.5 \sum_{i=1}^{5} g_{i}
$$

We followed the experimental design of Neugebauer, Perote, Schmidt and Malte (2009) and asked subjects to report the guess values of the mean group contribution after the decision-making in each round, and they received information feedback about the actual mean group contribution at the end of each round. Note that by requiring the reporting of the expected mean contributions, we might be forcing subjects to think more carefully about his/her economic decision than they otherwise would have. The total payoffs of a subject in each round included the payoffs from the group project as well as from guessing (Appendix $B$ provides the computational formula of the payoffs). At the end of the experiment, the final payoff each subject received was his/her average payoff over 30 rounds 5 .

\section{Results}

In this section, we provide detailed descriptions and statistical tests of the results. We focused on the behavioral differences from the experiment in Section 3.1. In section 3.2, we assessed to what extent the corresponding indicators from PPS were responsible for the behavioral differences associated with ethnicity observed in the experiment. A description of the variables is presented in Table 1.

\section{Results from experiment on behavioral differences}

\section{A. Are there any differences in the trends of the contributions over time between ethnicities?}

Result A: The results from the ethnic Bouyei and Han are supportive of declining trends of contributions, whereas the results from ethnic Zang show a roughly increasing trend. Moreover, the guess values gradually decrease over time for all ethnicities.

The three ethnicities exhibited distributions with no contributions at full-riding and full cooperation. The results from the total sample did not strongly support the declining trend of contributions, and trends were

\footnotetext{
${ }_{4}^{4}$ 'RMB' is the Chinese currency, and the exchange rate was 6.1 RMB per dollar in November, 2014. Herein, we provide both values as RMB (US\$).

${ }^{5}$ The final payoff each subject received was determined by the total payoff of the whole game (e.g., Putterman L and Anderson, 2006; Neugebauer, Perote, Schmidt and Malte, 2009) rather than in a random manner (e.g., Anderson, Mellor and Milyo, 2008) because in each round, participants may believe that there is a low possibility (1/30) that this round will be selected and hence do not treat it carefully. Hence, the final payoff is determined by the average payoff of 30 rounds in our experiment.
} 
prominently different between ethnicities. Interestingly, the contributions in the first round over all three sessions were very close among ethnicities and are approximately $1 / 3$ of the endowments (17RMB (2.8US\$)), which demonstrated an imprinted tendency to cooperate. Afterwards, the ethnic Bouyei and Han exhibited a declining trend with strong regularity, as observed in previous studies. We believed that this less cooperative behavior arose from the gradual mistrust in others over time rather than out of punishment of others ${ }^{6}$. The mistrust led to the instinctive human desire for self-preservation which is the fundamental behavioral principle of humanity under 'Hobbes Jungle' that approximates our design with absence of formal social norm (such as no design of punishment rules) argued by Hobbes $\mathrm{T}$ and Jean-Jacques Rousseau (this argument is cited from Meng Li, 2013). However, even under the mechanism of information feedback, the cooperation level of the ethnic Zang roughly showed a rising trend. Additionally, in contrast to the ex ante unknown number of periods (Fehr and Gächter, 2000), we deliberately designed the experiment with ex ante known and found that the most generous cooperation occurred at the final round for the ethnic Zang and Bouyei. Some other studies have also detected the same phenomenon in experiments and explained that many subjects are willing to have a final attempt (Zhou and Song, 2008). Nevertheless, we provided a plausible reason, on the basis of our informal return visit, that some subjects who contributed less over time would feel guilt that they had reduced the group's payoff once. This may led to the highest contributions of them out of the intention of compensation at the final round.

\section{B. Do behavioral differences between group structures exist? And ethnic difference in contribution depends on group structure?}

Result B: Ethnic diversity did not necessarily reduce the level of cooperation, and ethnic dominance may pose a greater barrier to cooperation. However, ethnic dominance merely had an overall effect; i.e., it decreased contributions of all subjects in GS3 and did not change the subjects' relative contribution between the group structures in which his/her ethnicity was designed as dominant and minor ones. There were remarkable ethnic differences in contributions in most situations, and the two largest differentiations both appeared in the GS3 (between the Zang and other two ethnicities). However, when subjects acted as minor ethnicities in GS3, the differences between ethnicities vanished.

A few studies have shown that ethnic diversity frequently reduces team performance in both public and private sectors (Watson, Kumar and Michaelsen, 1993; Pelled, Eisenhardt and Xin, 1999; Pitts and Jarry, 2007; Castro, 2008; Hur, 2013), whereas the conservative estimates of the experimental study by Waring and Bell (2013) indicates that ethnic dominance has a much larger negative effect on contributions in the public goods experiment than does caste diversity in India. We found multi-faceted results for different ethnicities in our study. Statistical power analysis of the non-parametric Mann-Whitney U(MWU) test cannot reject the null hypothesis that contributions of the ethnic Zang between group structures come from the same distribution, which means ethnic diversity has no significant effect on the level of cooperation of ethnic Zang (the mean contributions in GS1, GS2 and GS3 were 16.7RMB (2.74US\$), 17.4RMB (2.85US\$) and 16.9RMB (2.77US\$), respectively). However, we found that contributions were significantly different between all group structures for ethnic Bouyei, which confirms group structure-bias (the mean contributions in GS1, GS2 and GS3 were 15.0RMB (2.46US\$), 18.5RMB (3.03US\$) and 13.2RMB (2.16US\$), respectively). The mean level of contribution in GS2 was the statistically highest, which suggests that the ethnic Bouyei regard a group structure composed of their own ethnicity members more favorably than the other two group structures. By contrast, ethnic diversity promoted the cooperation of ethnic Han (the mean contributions in GS1, GS2 and GS3 were 17.5RMB (2.87US\$), 15.8RMB (2.59US\$) and 13.6RMB (2.23US\$), respectively). We may thus conclude that the ethnic interactions entail additional complexities rather than one single law. The statistical results from the ethnic Han conflict with the conjecture that the lowest level of cooperation would appear in GS1: GS1 had the highest degree of diversity but prior researchers have suggested that humans cooperate more with in-group members (de Cremer and Vugt, 1999; Goette et al., 2006).

\footnotetext{
${ }^{6}$ However, another possible reason to explain the reduction in contribution over time is that subjects are willing to punish free-riders. The less contribution he/she makes to the group account, the less payoff is received by the free-riders from free-riding. This is a potential way to punish free-riders in public good experiments without a punishment mechanism design, and humans reciprocate wrongs by harming the offender, even at a cost to themselves (Fehr and Gächter, 2000; de Quervain, Fischbacher, Treyer, Schellhammer, Schnyder, Buck, Fehr, 2004). However, we believe subjects' motivation to reduce contributions is out of gradual mistrust in others rather than punishment of free-riders, according to our informal callback survey that inquired about the motivation of subjects to reduce contributions.
} 
In contrast, ethnic dominance may pose a greater barrier to cooperation than ethnic diversity, and cooperation is much more likely to be determined by interactions at a finer scale (Posner, 2004; Waring and Bell, 2013); we found that mean contributions in GS3 were lower than the other two group structures for the ethnic Bouyei and Han. We further computed P-values from $M W U$ to compare the contributions of subjects when acting as a dominant and as a minor affiliation in GS3. We found an interesting result: although ethnic dominance decreased cooperation, contributions under the two situations were not significantly different ( $\mathrm{p}=0.14,0.56$ for the ethnic Bouyei and Han, respectively). This result revealed that the only overall effects of ethnic dominance were that selfish-bias was more likely to be elicited by all members and the reduction in contributions affects all members rather than only the subjects from minor affiliations. This leaves open the possibility that people may be sensitive to the terms of the group structure (in terms of being a 'diverse group', 'homogeneous group' or 'one ethnic affiliation dominant group') rather than his/her ethnic affiliation status in terms of the composition of ethnic population.

We also found the evidence that group structure played an important role in determining the ethnic difference in contribution. The two greatest contribution gaps appeared in GS3 (between the ethnic Zang and Bouyei, differences in mean contributions in GS1, GS2 and GS3 were 1.7RMB (0.28US\$), -1.1RMB (-0.18US\$) and 3.7 RMB (0.61US\$), respectively) and between the ethnic Zang and Han, and the greater contribution gaps appear in GS2 than GS1 (differences in average contributions in GS1, GS2 and GS3 were -0.8RMB ($0.13 \mathrm{US} \$$ ), 1.6RMB (0.26US\$) and 3.3RMB (0.54US\$), respectively). Besides, we found an interesting result that acting as the minor ethnicity in GS3, there were insignificant differences in contribution between ethnicities, i.e., the behaviors of all ethnicities exhibited consistency ( $\mathrm{p}=0.19$ between Zang and Bouyei, and $\mathrm{p}=0.64$ between Bouyei and Han). The evidence from our experiment confirmed the importance of degree of ethnic diversity (or ethnic dominance) in determining ethnic differences on cooperative behavior.

\section{What forms of prosocial preferences are elicited in the experiment and was there any difference in their intensity between ethnicities?}

Result C: Reciprocity preference was generally observed over all group structures for all ethnicities, and it appeared to be stronger in GS1 than in GS2. The ethnic Zang generally showed larger coefficient of Guess than the other two ethnicities, which indicated their stronger reciprocity preference. Moreover, the results showed that subjects may harbor other forms of prosocial preferences besides reciprocity as the significant coefficients of AVReal ${ }_{\text {it- } 1}$, and a comparison of coefficients' size indicated that ethnic Bouyei and Zang reacted more intensively than the ethnic Han.

We divided the panel data by ethnic affiliation and estimated the following Eq.(2), which captured the panel data dynamics for the contributions. Eq.(2) explained subject's contributions in terms of their own past contributions, their guesses about average contributions and the lagged average contribution of group members. We used generalized method of moments $(G M M)$ to ensure the consistency of the parameter estimates of the corresponding dynamic panel data structures.

$$
C B_{i, t}=\alpha+\beta_{1} C B_{i, t-1}+\beta_{2} \text { Guess }_{i, t}+\beta_{3} \text { AVReal }_{i, t-1}+\varphi_{i}+\varepsilon_{i, t} \text { (2) }
$$

Ashraf, Bohnet and Piankov (2006) decompose prosocial preferences in dictator and trust games by phasesequence design and define trustor's expected value of the fraction returned by trustee as an independent variable of trust, which we infer may explain the conditional preference, i.e., reciprocity. Similarly, the guess value was regarded as a proxy indicator measuring the intensity of reciprocal preference in our experiment. More contributions would be made as a result of more expected contributions from others. The results showed that reciprocal preference was observed over nearly all group structures and was strongest in GS1 for all ethnicities, which remarkably indicated that subjects reciprocated more in ethnically diverse than in ethnically homogeneous groups (See Table 4). This result contradicted our expectation that the strongest reciprocity would occur in GS2. Although acting as minor affiliations in GS3, the ethnic Bouyei and Han also exhibited strong reciprocal preferences. By contrast, for the ethnic Zang, the contributions were uncorrelated with the guesses, which demonstrated the constant intensity of this preference: no matter how much the dominant ethnicity contributed to the group account, the contributions elicited by reciprocity preferences remained unchanged $(p=0.28)$. On the whole, the ethnic Zang may have a stronger reciprocal preference 
because the coefficients of 'Guess' were generally larger in magnitude than other two over all group structures.

We were able to trace unconditional prosocial preferences by specifying lagged AVReal $_{i t-1}$ in regression models. The lagged $A V R e a l_{i-1}$ was expected to be uncorrelated with $C B$ because the groups were randomly assigned in each round. However, the result conflicted with our expectation in GS2. The negative sign of the coefficients of lagged AVReal $_{i t-1}$ demonstrate that the lower average contribution to the group account in the last round increased one's contribution in the following round even if the group had been randomly reassigned. The subjects may harbor unconditional emotions such as earning inequality aversion, hoping that earning was fairly assigned to the members of his/her own ethnicity when they lie in a homogeneous group, and this allowed us to conjecture that a shared ethnic affiliation may serve as coordination devices for shared expectations, namely the pursuit of earning equality. A comparison of the size of the coefficients between the ethnicities suggests that the ethnic Bouyei and Zang reacted more intensively than the ethnic Han.

The Results of Assessing the Explanatory Power of Culture: After discussing the differences in prosocial behavior between ethnicities based on the public good provision experiment, next we identified the cultural explanatory variables for the behavioral differences, and we conducted our analysis as follows: (1) First we examined whether the ethnic affiliation itself predicted the observed behavioral difference. To accomplish this task, we regressed the contribution to the group account exclusively on subject ethnic affiliation and other variables controlling for individual characteristics because ethnic affiliation is considered to be aggregative predictor for culture and is normally characterized in terms of culture (Betancourt and Lopez, 1993) (See results of Model 1 in Table 6). Regressing the contribution on a dummy variable for subject ethnic affiliation resulted in coefficients with strong explanatory power (the ethnic affiliation predicted differences in contributions between the ethnic Zang and Bouyei at 1\% significance and between the ethnic Zang and Han at $5 \%$ significance). Additionally, we also found that two variables of individual characteristics, major and gender, were responsible for the cooperative behavior.

(2) Although ethnic affiliation per se provided strong explanatory power, our task was to investigate how culture operated. We decomposed the conception of culture into five dimensions grouped by measurable variables and then measured their ability to explain behavioral differences ('Participation', 'Outgroup Rejection', 'Religion', 'Market Interaction' and 'Centralization of Power'). Before carrying out this measurement, we assessed to what extent cultural differences exist between ethnicities in terms of their responses to these cultural questions. We subjected each group of items to separate factor analysis and used the Varimax rotation method to obtain parsimonious factor solutions and retained only those with eigenvalues greater than 1.5 (these factors and the individual items that constitute them are outlined in Appendix $A$ ). Afterwards, a series of Mann-Whitney tests were conducted on differences in scores between ethnicities (See Table 5). The results showed that there was no significant difference in terms of $P C$ ('Participation') in a range of voluntary associations ( $p=0.26$ for Zang vs. Bouyei; $p=0.13$ for Bouyei vs. Han; $p=0.71$ for Han vs. Zang) as well as $O R$ ('outgroup rejection') in a range of living environments with different types of neighbors ( $\mathrm{p}=0.86$ for Zang vs. Bouyei; $\mathrm{p}=0.18$ for Bouyei vs. Han; $\mathrm{p}=0.28$ for Han vs. Zang) between all ethnicities. Moreover, we found the ethnic Zang and Han were statistically the most and least religious respectively based on the comparison of $R L$ ('Religion'). We also found that the ethnic Han showed the highest level of involvement in market economies ('Market Interaction') , but there was no evidence of differences between the ethnic Bouyei and Zang ( $p=0.9$ for Zang vs. Bouyei; $p=0.10$ for Bouyei vs. Han; $p=0.09$ for Han vs. Zang). Finally, the ethnic Zang also exhibited a higher degree of centralization of power of family ('Centralization of Power', $\mathrm{p}=0.04$ for Zang vs. Bouyei; $p=0.57$ for Bouyei vs. Han; $p<0.01$ for Han vs. Zang). We dropped the insignificant cultural factors, $P C$ and $O R$, and then regressed the contribution on the remaining ones and their interaction terms with ethnic affiliation, while still keep ethnic affiliation and other variables controlling for individual characteristics in the regression model (see the results of Model 2 in Table 6),

$$
\begin{aligned}
C B_{i} & =\alpha+\beta_{1} R L_{i}+\beta_{2} M I_{i}+\beta_{3} C P_{i}+\beta_{4} E A_{i} \times R L_{i}+\beta_{5} E A_{i} \times M I_{i} \\
& =\beta_{6} E A_{i} \times C P_{i}+\beta_{7} E A_{i}+\beta_{8} M J_{i}+\beta_{9} G D_{i}+\beta_{10} E P_{i}+\beta_{11} E Y_{i}+\beta_{12} G S+\varepsilon_{i} \text { (3) }
\end{aligned}
$$

By decomposing culture, The results showed that the cultural factors also provided powerful predictors, based on the observed significant values of interaction terms (cultural factors interacted with ethnic affiliation); however, once they are specified in the regression model, the values of the coefficients of $E A$ 
(ethnic affiliation) varied significantly, but the adjusted $R^{2}$ varied relatively little (the adjusted $R^{2}$ of Model 1 and Model 2 were 0.29 and 0.35, respectively, and the coefficients of individual characteristic variables were not sensitive to this change). This may imply multicollinearity, and therefore we next regressed $E A$ on all cultural factors and found all of them were significantly correlated to $E A$. This result may suggest that a particular set of measurable variables identified in our survey is capable of serving as proxies for the cultural influences on economic behavior ${ }^{7}$. Interestingly, we found the differences in the three dimensions of culture, $R L, M I$ and $C P$ may not give rise to the behavioral differences between the two minor ethnicities (the ethnic Zang and Bouyei (all the coefficients of the three dimensions interacted with ethnic affiliation were insignificant at 10\%)), whereas the impacts of cultural differences on behavioral differences are generally strong between the two minor ethnicities and the ethnic Han (the coefficients of $E A \times R L$ and $E A \times M I$ are significant at $1 \%$, and the coefficients of $E A \times C P$ is significant at $10 \%$ between the ethnic Zang and Han). The negative effect of its interaction with ethnic affiliation indicates that religious attitudes of the minor ethnicity may influence economic prosocial behavior more strongly than among the ethnic Han. Although the role of a religion might depend highly upon ethnic affiliation, it operates in different ways.

Ethnic Zang believe in Mahayana Buddhism that people pray for delivering all living creatures from torment as the highest priority of spiritual practice rather than for themselves (which is the practice of ethnic Han) (Hua, 2013) that may induce stronger economic prosociality. Ethnic Bouyi practice polytheistic worship (State Nationalities Affairs Commission, 2008) and we conjecture this religious sentiment that reveres the nature influences the prosocial disposition. The result from the negative sign and strong significance of the coefficients for $M I$ deviates from the finding of Henrich et al (2001) and suggests that more self-regarding preferences may be elicited by higher level of market interactions. Nevertheless, a self-regarding preference is elicited less for the two minor ethnicities compared to the ethnic Han by market interaction because only the interaction effect between $E A^{3}$ and $M I$ is significant and has a positive coefficient. The same is true for centralization of power of a family. The larger magnitude of $C P$ indicates that the subjects who suffer more from tyranny in family relations may behave in a more other-regarding manner because we found the sign of $C P$ was positive and significant at $1 \%$, and the effect of $C P$ on prosocial behavior differed weakly depending on the subject's ethnic affiliation. The negative sign of the interaction effect between ethnic affiliation and centralization of power of a family $\left(E A^{3} \times C P\right)$ means $C P$ had less impact on the two minor ethnicities compared to the ethnic Han.

(3) Actually, we had not addressed GS (group structure), which we viewed as a very important implicit cultural factor for measuring ethnic identity (ethnic prejudice). We generated various composition of groups in terms of ethnic proportions to determine indirectly how ethnic identity (or prejudice) as an additional cultural factor accounts for behavioral differences. To accomplish this task, we ran another regression model including group structure as a dummy variable (See results of Model 3 in Table 6). We noticed that the results of Model 2 and Model 3 were robust in terms of sign, magnitude and statistical significance of coefficients for the previous five cultural factors and their interactions with ethnic affiliation and variables of individual characteristics as well. However, the values of the coefficients of $E A$ (ethnic affiliation) varied significantly accordingly, whereas the adjusted $R^{2}$ of the model varied only slightly (the adjusted $R^{2}$ of Model 2 and Model 3 were 0.35 and 0.42 , respectively). We then regressed $E A$ on all the cultural factors as well as $G S$ and found that $E A$ had a significant correlation with GS. This also suggests that $G S$ is capable of accounting for $E A$. These results of analysis from Model 3 confirmed what we detected from the economic experiment in a statistical manner that group structure was responsible for the behavioral differences on the basis of the significant coefficients of the interaction term $(E A \times G S)$. For example, the statistical results showed that as the differences in contributions in GS1 between the ethnic Zang and other two ethnicities are defined as reference points $\left(E A^{2} \times G S^{1}, E A^{3} \times G S^{1}\right)$, the switch of group structure from GS1 to GS2 induced an increase in contribution differences between the ethnic Zang and Bouyei (the coefficient is 3.16 significance at $5 \%$ ) and a decrease in contribution differences between the ethnic Zang and Han (the coefficient is -2.62 significance at $10 \%$ ). The plausible reason was the sentiment towards ethnic composition varies in ethnic affiliation that leads to behavioral difference. As a whole, all cultural factors were responsible for behavioral differences between the ethnic Han and the two minor ethnicities (the interaction effect between any of the cultural factors was

${ }^{7}$ The adjusted $\mathrm{R}^{2}$ of the regression model is far below 1 also indicated there were still other potential variables accounting for culture that we did not identify. 
significant at $10 \%$ at least), and it was interesting that the behavioral difference was attributed to the group structure between the two minor ethnicities only.

\section{Conclusion and Discussion}

A number of public good provision experiments confirm the existence of prosocial behavior because the contribution proportions are more than nothing, but interestingly, it declines with repetition and converges to lower levels (Isaac, Walker and Thomas, 1984; Andreoni, 1988; Andreoni, 1995; Sonnemans, Schram and Offerman, 1999; Fischbacher, Gächter and Fehr, 2001). Other mechanisms need to be developed to prevent the reduction of public good provisions in the game, such as voluntary punishment (Forsythe, Horowitz, Savin and Sefton, 1994; Fehr and Gächter, 2002; Andreoni and Miller, 2002; Falk, Fehr and Fischbacher, 2005; Bochet, Page and Putterman, 2006; Carpenter, Bowles, Gintis and Hwang, 2009; Choi and Ahn,2003) and full refund rules (Isaac, Schmidtz, Walker, 1989; Bagnoli and McKee, 1991). However, we found evidence of a roughly increasing trend over time for ethnic Zang in a game without any anti-declining mechanism ${ }^{8}$, even if they expected self-regarding behavior in strangers. In contrast, the other two ethnicities presented clearly declining trends of contributions, which exhibited the more self-regarding preference over time in comparison. Group structure varying in ethnic composition strengthens the fascination regarding human nature. It appears, based on our data, that three distinct degrees of ethnic diversity (or ethnic dominance), i.e., compositions of groups in terms of ethnic proportions, influence cooperative behavior in different ways, and we found diverse results. Evolutionary theory suggests that humans have evolved to create ethnic groups for stabilized cooperation and solving collective action problems related to adaptive challenges (Wilson and Wilson, 2007; Waring and Bell, 2013). However, ethnic dominance posed a remarkably greater barrier to cooperation than ethnic divisions between group structures for the ethnic Bouyei and Han. Reduction in ethnic diversity to homogeneous groups (from GS1 to GS2) did not increase contributions for the ethnic Zang and Han compared to the increase for the ethnic Bouyei.

Moreover, it was noteworthy that the term of ethnic composition ('diverse', 'homogeneous' or 'dominant' which can be collectively termed as 'group structure-bias') may play a more important role in determining behavioral patterns than 'individual-bias'(due to identity or prejudice to individuals out of his/her ethnic affiliation as some studies claim (Becker, 1957, 1993; Fershtman and Gneezy, 2014)) because we found that subjects of the two minor ethnicities acting as the dominant ethnicity in GS3 contributed much less than they did in GS1. Meanwhile, we also found that the ethnic Han contributed more in GS1 than in GS2, in contrast to the argument that ethnic identity is a means to create boundaries that enable a group to distance themselves from one another (Barth, 1969). Additionally, by using guess values as an independent variable to isolate reciprocity preferences from other possible forms of prosocial preference using model regression, we found clear evidence that the reciprocity norm was behaviorally relevant. The reciprocity preference exists in all ethnicities across all group structures because marginal effects of Guess $i t$ were generally over 0.5; overall, the ethnic Zang exhibited the strongest reciprocity preference. Moreover, there was clear evidence in our data that were other forms of prosocial preference besides reciprocity, as demonstrated by the negative correlation between $C B_{i t}$ and lagged AVReal ${ }_{i t-1}$ in GS2. In general, we have shown based on the results of the experiments that people may harbor various forms of prosocial emotions in economic affairs, and especially exhibit stronger at the initial phase rather than what the textbook representation of Homo economics predicts.

Culture is a useful variable to uncover economic behavior, and a stream of studies is in favor of this viewpoint (e.g., Chuah, Hoffmann, Jonesb and Williams, 2009). We found supportive evidence from our empirical results that a particular set of measurable factors identified as proxies for cultural influence statistically accounted for ethnic differences in prosocial behavior. A wave of recent studies confirm the impact of religion on prosociality; religious people demonstrate highly prosocial behavior (Georgianna, 1984; Darley and Batson,

${ }^{8}$ Actually, we designed an aid-declining mechanism in the game, namely an information feedback mechanism, in which subjects received information about payoffs and partners' contributions until the end of the experiment, and the evidence from Neugebauer T, Perote J, Schmidt U and Malte L (2009) suggest that this mechanism is destructive to efficiency. 
1973, Bushman et al., 2007; Saroglou et al., 2009). However, it facilitates in different manners as the differences in doctrine and variability in concerned deities and this may also influence prosociality.

Our results on the market interaction from the whole sample contradicted the findings of Henrich et al. (2001), which found strong evidence that prosocial norms increase with greater market integration and other studies also confirm the positive impact of market-based elements, such as competitiveness and marketcentric language, on prosocial preferences (Chen, 2010; Al-Ubaydli et al., 2013). However, when we regressed the three ethnic affiliation samples separately, the results were multi-faceted. The results showed that the coefficients of $M I$ are negative $(-1.54(\mathrm{p}<0.01)$ for the ethnic Zang and $-0.65(\mathrm{p}=0.09)$ for the ethnic Bouyei), whereas it is positive for the ethnic Han $(1.33(\mathrm{p}<0.01))$. We made an informal return visit to subjects to inquire about their views on this. Interestingly, we received the unanimous response of two minor ethnicities that they did not have faith in the power of the market economy to develop prosocial norms. They considered the market economy to be filled with deception, mistrust and mutual hurt, and expect it to induce indifference, callousness and the moral decline of human nature. However, the ethnic Han stated that the market economy achieves reciprocity. As the ethnic Han are more involved in the market economy, based on the larger magnitude of $M I$, we believed it may give rise to stronger reciprocal preferences. Few studies have addressed the impact of centralization of family authority with reference to the impact of democracy and freedom on individual prosocial preference, as we have learned. Weber, Unterrainer and Schmid (2009) investigate whether organizational democracy influences the development of a social-moral climate and prosocial behavioral orientation, and the findings suggest that as the level of participation in decision-making processes increase, higher levels of prosocial and community-related behavioral orientations (characterized by behaviors such as mutual help and solidarity) are exhibited. By contrast, other research on children's prosocial behavior claims that the degree of democracy in the family is irrelevant to prosociality (Li, 2000). However, our results from this economic experimental study suggest on the contrary that lower participation in decision-making of significant family affairs induced by centralized authority was associated with higher levels of economic prosociality and may impact minor ethnicities more because the results showed a positive sign of coefficient of $C P$ and a negative sign of coefficient of the interaction term, $E A^{3} \times C P$, although it is relatively weak. These findings from the economic anatomy of culture support the contention that some dimensions of culture play an important role in affecting the cooperative behavior, and more crucially, they may have different marginal effects in magnitude between ethnicities and may even affect in opposite ways as what we have detected from the results of MI. It shows the diverse ways of cultural influence in shaping prosocial behaviors between ethnicities.

The research limitations of our study lie particularly in the design of the questions on religion, market interaction and centralization power of family, which were relatively crude and therefore may have impacted or influenced the interpretation of the findings. The definition of the word 'god' varies throughout the various religious traditions of China; for example, the ethnic Zang believe in the Indian Mahayana form of Buddhism, whereas the ethnic Bouyei believes in many gods (e.g., River, Lake or Pond). There are probably different affect and comprehension of gods across ethnicities; further work is necessary to make distinguishing questionnaires on the basis of notions of god. We merely selected necessary questions to measure market interaction and ignored other economic variables such as capital loans. The centralized authority of family may take the form of imposing values on family members, and it should also be considered. Additionally, we only addressed some dimensions of culture in terms of prosociality by measurable variables; more complete approach is required to explore the missing dimensions of culture.

Acknowledgments: This work was supported by the Academic Degree Program of Applied Economics, Southwest University for Nationalities under Grant [number 2014XWD-S0202].

\section{References}

Andreoni, J. \& Schols, J. K. (1990). An Economic Analysis of Charitable Giving With Interdependent Preferences, Working papers 90-23, Wisconsin Madison-Social Systems.

Andreoni, J. \& Miller, J. (2002). Giving According to GARP: An Experimental Test of the Consistency of Preferences for Altruism. Econometrica, 70(2), 737-53. 
Andreoni, J. (1995). Cooperation in Public Goods Experiments: Kindness or Confusion? American Economic Review, 85(4), 891-904

Andreoni, J. (1988). Why Free Ride? Strategies and Learning in Public Goods Experiments. Journal of Public Economics, 37(3), 291-304.

Ashraf, N., Bohnet, I., \& Piankov, N. (2006). Decomposing trust and trustworthiness. Experimental Economics, 9(3), 193-208.

Bagnoli, M., \& McKee, M. (1991). Voluntary Contribution Games: Efficient Private Provision of Public Goods. Economic Inquiry, 92(2), 351-366.

Barth, F. (1969). Ethnic groups and boundaries: The social organization of culture difference. Boston: Little, Brown, \& Co.

Becker, G. (1957). The economics of discrimination. University of Chicago Press, Chicago.

Becker, G. (1993). The evidence against Banks Doesn't prove bias. Business Week, 19(4), 18

Benjamin, D. J., Choi, J. J. \& Fisher, G. (2013). Religious identity and economic behavior. Cornell University mimeo, August. Revise and resubmit, Review of Economics and Statistics.

Betancourt, H. \& Regeser, L. S. (1993). The Study of Culture, Ethnicity, and Race in American Psychology. American Psychologist, 48(6), 629-637.

Botelho, A., Harrison, G. W., Pinto-Costa, L. M. \& Rutström, E. E. (2009). Testing Static Game Theory with Dynamic Experiments: A Case Study of Public Goods. Games and Economic Behavior, 67(1), 253-265.

Burlando, R. \& Hey, J. (1997). Do Anglo-Saxons Free-Ride More? Journal of Public Economics, 64(1), 41-60.

Camerer, C. (1997). Progress in Behavior Game Theory. Journal of Economic Perspectives, 11(4), 167-188.

Cameron, L. (1999). Raising the stakes in the ultimatum game: Experimental evidence from Indonesia. Economic Inquiry, 37(1), 47-59.

Cason, T. J., Saijo, T. \& Yamato, T. (2002). Voluntary Participation and Spite in Public Good Provision Experiments: An International Comparison. Experimental Economics, 5(2), 133-153.

Castro, M. F. (2008). Where Are You From? Cultural Differences in Public Good Experiments. The Journal of Socio-Economics, 37(6), 2319-2329.

Chen, Y. (2010). Test of Social Preferences: An Experimental Study Beyond Homo Economics. Dissertation, Zhejiang University, China. (In Chinese)

Choi, J. K. \& Ahn, T. K. (2003). Strategic Reward and Altruistic Punishment Support Cooperation in A Public Goods Game Experiment. Journal of Economic Psychology, 35 (C), 17-30.

Chuah, S. W., Hoffmann, R., Jonesb, M. \& Williams, G. (2009). An economic anatomy of culture: Attitudes and behavior in inter-and intra-national ultimatum game experiments. Journal of Economic Psychology, 30(5), 732-744.

Darley, J. M. \& Batson, C. D. (1973). From Jerusalem to Jericho: a study of situational and dispositional variables in helping behavior. Journal of Personality and Social Psychology, 27(1), 100 -8.

De Cremer, D. \& Van-Vugt, M. (1999). Leadership in social dilemmas: the effects of group identification on collective actions to provide public goods. Journal of personality and social psychology, 76(4), 587599.

Falk, A., Fehr, E. \& Fischbacher, U. (2005). Driving Forces behind Informal Sanctions. Econometrica, 73(6), 2017-2030.

Falk, A. \& Fischbacher, U. (2006). A Theory of Reciprocity. Games and Economic Behavior, 54(2), 293-315.

Fehr, E. \& Gächter, S. (2002). Altruistic Punishment in Humans. Nature, 415(10), 137-140.

Fehr, E. \& Gächter, S. (2000). Cooperation and Punishment in Public Goods Experiment. American Economic Review, 90(4), 980-994.

Fehr, E. \& Schmidt, K. (1999). A Theory of Fairness, Competition and Cooperation. Quarterly Journal of Economics, 114(3), 817-868.

Fenton, S. (2010). Ethnicity (second edition). Polity Cambridge, UK.

Fershtman, C. \& Gneezy, U. (2014). Discrimination in a segmented society: an experimental approach. The Quarterly Journal of Economics, 116(1), 351-377.

Fischbacher, U., Gächter, S. \& Fehr, E. (2001). Are People Conditionally Cooperative? Evidence from A Public Goods Experiment. Economics Letters, 71(3), 397-404.

Georgianna, S. L. (1984). Is a religious neighbor a good neighbor? Humbolt Journal of Social Relations, 11(2), 1 $-16$.

Glaeser, E. L., Laibson, D. I., Scheinkman, J. A. \& Soutter, C. L. (2000). Measuring Trust. Quarterly Journal of Economics, 65(3), 811- 846 
Hang, Y., Dingding, W. \& Weidong, L. (2005). On Endogenetic Preference for Altruism Behaviors and Its Implications to Economics. Economic Research Journal (of China), 8, 84-94 (In Chinese).

Henrich, J., Boyd, R., Bowles, S., Camerer, C., Fehr, E., Gintis, H. \& McElreath, R. (2001). Reciprocity and Punishment in Fifteen Small scale Societies. American Economic Review, 91(2), 73-78.

Henrich, J. (2000). Does Culture Matter in Economic Behavior? Ultimatum Game Bargaining Among the Machiguenga of the Peruvian Amazon. American Economic Review, 90(4), 973-979.

Hofstede, G. (2011). Dimensionalizing Cultures: The Hofstede Model in Context. Online Readings in Psychology and Culture, 2(1). http://dx.doi.org/10.9707/2307-0919.1014.

Hua, Z. (2013). Brief History of Ethnic Zang. Nationalities Publishing House, Beijing, 2013

Hur, Y. (2013). Racial diversity, is it a blessing to an organization? Examining its organizational consequences in municipal police departments. International Review of Administrative Sciences, 79(1), 149-164.

Inglehart, R. (1997). Modernization and post modernization: Culture, economic, and political change in 43 societies. Princeton, NJ: Princeton University Press.

Isaac, R. M., Walker, J. M. \& Thomas, S. (1984). Divergent Evidence on Free Riding: An Experimental Examination of Some Possible Explanations. Public Choice, 43(2), 113-149.

Levinson, D. J. \& Peng, K. (2007). Valuing cultural differences in behavioral economics. The ICFAI Journal of Behavioral finance, 4(1), 32-47.

Li, D. (2000). A study of factors influencing the prosocial behavior of children. Psychological Science, 23(3), 285-381. (in Chinese)

Goette, L., Huffman, D. \& Meier, S. (2006). The impact of group membership on cooperation and norm enforcement: evidence using random assignment to real social groups. American Economic Review, 92(2), 212-216

Guiso, L., Sapienza, P. \& Zingales, L. (2006). Does culture affect economic behavior? Working paper.

Meng, L. (2013). The state of nature as the state of war: Hobbes's two arguments on the reconstruction of humanity. Journal of Yun Nan university, 13(5), 3-22 (In Chinese).

Miller, J. G. (1984). Culture and the Development of Everyday Social Explanation. Journal of Personality and Social Psychology, 46(5), 961-978.

Neugebauer, T., Perote, J., Schmidt, U. \& Malte, L. (2009). Selfish-Biased Conditional Cooperation: On The Decline of Contributions in Repeated Public Goods Experiments. Journal of Economic Psychology, 30(1), 52-60

Ockenfels, A. \& Weimann, J. (1999). Types and Patterns: An Experimental East-West- German Comparison of Cooperation and Solidarity. Journal of Public Economics, 71(2), 275-287.

Pelled, L. H., Eisenhardt, K. M. \& Xin, K. R. (1999). Exploring the black box: An analysis of work group diversity, conflict and performance. Administrative Science Quarterly, 44(1), 1-28.

Pitts, D. \& Jarry, E. (2007). Ethnic diversity and organizational performance: Assessing diversity effects at the managerial and street levels. International Public Management Journal, 10(2), 233-254.

Posner, D. M. (2004). The political salience of cultural difference: Why Chewas and Tumbukas are allies in Zambia and adversaries in Malawi. American Political Science Review, 98(4), 529-545.

Saroglou, V., Corneille, O. \& Van Cappellen, P. (2009). Speak, Lord, your servant is listening: Religious priming activates submissive thoughts and behaviors. International Journal for the Psychology of Religion, $19(3), 143-154$.

Shweder, R. A. (1990). Cultural Psychology - What Is It, in Stigler, J W, Shweder, R A and Herdt, G (eds.), Cultural Psychology: Essays on Comparative Human Development, pp. 1-43, Cambridge University Press, New York.

Sonnemans, J., Schram, A. \& Offerman, T. (1999). Strategic Behavior in Public Good Games: When Partners Drift Apart. Economics Letters, 62(1), 35-41.

Sosis, R. \& Ruffle, B. J. (2004). Ideology, religion, and the evolution of cooperation: Field tests on Israeli kibbutzim. Research in Economic Anthropology, 23, 89-117.

State Nationalities Affairs Commission. Brief History of Ethnic Bouyei, Nationalities Publishing House, Beijing, 2008.

Triandis, H. C. (1995). Individualism and Collectivism. Boulder, CO: Westview Trust. Quarterly Journal of Economics, 65(3), 811- 846.

Waring, T. M. \& Bell, A. V. (2013). Ethnic dominance damages cooperation more than ethnic diversity: results from multi-ethnic field experiments in India. Evolution and Human Behavior, 34(6), 398-404. 
Watson, W. E., Kumar, K. \& Michaelsen, L. K. (1993). Cultural diversity's impact on interaction process and performance: Comparing homogeneous and diverse task groups. Academy of Management Journal, 36(3), 590-602.

Wilson, D. S. \& Wilson, E. O. (2007). Rethinking the theoretical foundation of sociobiology. The Quarterly Review of Biology, 82(4), 327-348.

Wolfgang, G. W., Christine, U. \& Schmid, B. E. (2009). The Influence of Organizational Democracy on Employees' Socio-moral Climate and Prosocial Behavioral Orientations. Journal of Organizational Behavior, 30(8), 1127-1149.

Zhou, Y. \& Song, Z. (2008). The Voluntary Contribution Mechanism of Public Goods: An Experimental Research. Economic Research, 90-104. (In Chinese)

Table 1: Descriptions of variables

\begin{tabular}{|c|c|c|}
\hline Variable & & Description \\
\hline \multirow{4}{*}{$\begin{array}{l}C B \\
\text { Contribution to group } \\
\text { account }\end{array}$} & $Z-C B$ & $\begin{array}{l}\text { Mean contribution to group account of all ethnic Zang subjects } \\
\text { over } 10 \text { rounds in all sessions }\end{array}$ \\
\hline & $B y-C B$ & $\begin{array}{l}\text { Mean contribution to group account of all ethnic Bouyei } \\
\text { subjects over } 10 \text { rounds in all sessions }\end{array}$ \\
\hline & $H-C B$ & $\begin{array}{l}\text { Mean contribution to group account of all ethnic Han subjects } \\
\text { over } 10 \text { rounds in all sessions }\end{array}$ \\
\hline & Total-CB & $\begin{array}{l}\text { Mean contribution to group account of all subjects over } 10 \\
\text { rounds in all sessions }\end{array}$ \\
\hline \multirow{4}{*}{$\begin{array}{l}\text { Guess } \\
\text { Guess value of mean } \\
\text { group contribution }\end{array}$} & Z-Guess & $\begin{array}{l}\text { Mean guess value of all ethnic Zang subjects over } 10 \text { rounds in } \\
\text { all sessions }\end{array}$ \\
\hline & By-Guess & $\begin{array}{l}\text { Mean guess value of all ethnic Bouyei subjects over } 10 \text { rounds in } \\
\text { all sessions }\end{array}$ \\
\hline & H-Guess & $\begin{array}{l}\text { Mean guess value of all ethnic Han subjects of over } 10 \text { rounds in } \\
\text { all sessions }\end{array}$ \\
\hline & Total-Guess & Mean guess value of all subjects over 10 rounds in all sessions \\
\hline AVReal & & Mean contribution to group account of five subjects in a group \\
\hline & & GS1='diverse group'; \\
\hline Group Structure & & $\begin{array}{l}G S 2=\text { 'homogeneous group'; } \\
G S 3=\text { 'one ethnic affiliation dominant group' }\end{array}$ \\
\hline$E A$ & & Ethnic affiliation \\
\hline$P C$ & & Cooperation \\
\hline OR & & Outgroup Rejection \\
\hline$R L$ & & Religion \\
\hline MI & & Market interaction \\
\hline$C P$ & & Centralization of power of a family \\
\hline MJ & & Major \\
\hline$G D$ & & Gender \\
\hline$E P$ & & Expenditure monthly \\
\hline$E Y$ & & Average years of education of family members \\
\hline$t, t-1$ & & The $t$ period, one period lagged \\
\hline
\end{tabular}

Table 2: Test on differences in contributions between three group structures.

\begin{tabular}{llllllllll}
\hline $\begin{array}{l}\text { Group } \\
\text { Structures }\end{array}$ & \multicolumn{2}{l}{ GS1 VS. GS2 } & \multicolumn{3}{c}{ GS2 VS. GS3 } & \multicolumn{3}{c}{ GS3 VS. GS1 } \\
\hline Ethnicity & Zang & Bouyei & Han & Zang & Bouyei & Han & Zang & Bouyei & Han \\
\hline Mann-Whitney & -0.37 & -3.70 & 1.36 & 0.36 & 6.16 & 3.01 & -0.02 & 1.91 & 3.94 \\
Test & $(0.70)$ & $(0.00)$ & $(0.17)$ & & $(0.00)^{* * *}$ & $(0.00)$ & $(0.98)$ & $(0.05)^{* *}$ & $(0.000)$ \\
& & & & $(0.71)$ & & & & & $* * *$ \\
\hline
\end{tabular}

a Z-values in parentheses. ${ }^{*}$ coefficient is significantly different from zero at 0.10 level. ${ }^{*}$ coefficient is significantly different from zero at 0.05 level. ${ }^{* * *}$ coefficient is significantly different from zero at 0.01 level. 
Table 3: Test on differences in contributions between ethnicities in various group structures.

\begin{tabular}{|c|c|c|c|c|c|c|c|c|c|}
\hline Ethnicity & Zang vs. & ouyei & & Bouye & s. Han & & Han vs & Zang & \\
\hline Group Structure & GS1 & GS2 & GS3 & GS1 & GS2 & GS3 & GS1 & GS2 & GS3 \\
\hline $\begin{array}{l}\text { Mann-Whitney } \\
\text { Test }\end{array}$ & $\begin{array}{l}2.03 \\
(0.04)^{* *}\end{array}$ & $\begin{array}{l}-1.186 \\
(0.235)\end{array}$ & $\begin{array}{l}3.89 \\
(0.00)\end{array}$ & $\begin{array}{l}-1.78 \\
(0.07)\end{array}$ & $\begin{array}{l}3.82 \\
(0.00)\end{array}$ & $\begin{array}{l}0.14 \\
(0.88)\end{array}$ & $\begin{array}{l}0.27 \\
(0.78)\end{array}$ & $\begin{array}{l}1.78 \\
(0.07)\end{array}$ & $\begin{array}{l}4.21 \\
(0.00) \\
* * *\end{array}$ \\
\hline
\end{tabular}

a P-values in parentheses. ${ }^{*}$ coefficient is significantly different from zero at 0.10 level. ${ }^{* *}$ coefficient is significantly different from zero at 0.05 level. ${ }^{* * *}$ coefficient is significantly different from zero at 0.01 level.

Table 4: Results of panel data regression

\begin{tabular}{|c|c|c|c|c|c|c|c|c|c|}
\hline \multirow{2}{*}{$\begin{array}{l}\text { Ethnicity } \\
\text { Dependent } \\
\text { variable } \\
\text { CB }_{\text {it }}\end{array}$} & \multicolumn{3}{|l|}{ Zang } & \multicolumn{3}{|l|}{ Bouyei } & \multicolumn{3}{|l|}{ Han } \\
\hline & GS1 & GS2 & $\begin{array}{l}\text { GS3 } \\
\text { Minor }\end{array}$ & GS1 & GS2 & $\begin{array}{l}\text { GS3 } \\
\text { Minor }\end{array}$ & GS1 & GS2 & $\begin{array}{l}\text { GS3 } \\
\text { Minor }\end{array}$ \\
\hline \multicolumn{10}{|l|}{$\begin{array}{l}\text { Independent } \\
\text { Variable }\end{array}$} \\
\hline $\mathrm{CB}_{\mathrm{it}-1}$ & $\begin{array}{l}0.18 \\
(0.00)^{* * *}\end{array}$ & $\begin{array}{l}0.17 \\
(0.00)^{* * *}\end{array}$ & $\begin{array}{l}-0.17 \\
(0.13)\end{array}$ & $\begin{array}{l}-0.08 \\
(0.12)\end{array}$ & $\begin{array}{l}0.39 \\
(0.00) \\
* * *\end{array}$ & $\begin{array}{l}-0.28 \\
(0.00) \\
* * *\end{array}$ & $\begin{array}{l}0.35 \\
(0.00) \\
* * *\end{array}$ & $\begin{array}{l}0.16 \\
(0.01) \\
* * *\end{array}$ & $\begin{array}{l}0.24 \\
(0.10)^{*}\end{array}$ \\
\hline Guess $_{\text {it }}$ & $\begin{array}{l}0.95 \\
(0.00)^{* * *}\end{array}$ & $\begin{array}{l}0.82 \\
(0.00)^{* * *}\end{array}$ & $\begin{array}{l}0.16 \\
(0.28)\end{array}$ & $\begin{array}{l}0.77 \\
(0.00)^{* * *}\end{array}$ & $\begin{array}{l}0.63 \\
(0.00)\end{array}$ & $\begin{array}{l}0.76 \\
(0.00) \\
* * *\end{array}$ & $\begin{array}{l}1.10 \\
(0.00) \\
* * *\end{array}$ & $\begin{array}{l}0.60 \\
(0.00)\end{array}$ & $\begin{array}{l}0.54 \\
(0.00) \\
* * *\end{array}$ \\
\hline AVReal $_{\text {it-1 }}$ & $\begin{array}{l}-0.10 \\
(0.27)\end{array}$ & $\begin{array}{l}-0.23 \\
(0.05)^{* *}\end{array}$ & $\begin{array}{l}0.09 \\
(0.59)\end{array}$ & $\begin{array}{l}-0.20 \\
(0.33)\end{array}$ & $\begin{array}{l}-0.29 \\
(0.04)^{* *}\end{array}$ & $\begin{array}{l}-0.33 \\
(0.01)\end{array}$ & $\begin{array}{l}-0.33 \\
(0.23)\end{array}$ & $\begin{array}{l}-0.19 \\
(0.07)^{*}\end{array}$ & $\begin{array}{l}-0.08 \\
(0.67)\end{array}$ \\
\hline Intercept & $\begin{array}{l}0.04 \\
(0.98)\end{array}$ & $\begin{array}{l}3.93 \\
(0.07)^{*}\end{array}$ & $\begin{array}{l}13.94 \\
(0.00)\end{array}$ & $\begin{array}{l}9.04 \\
(0.00)^{* * *}\end{array}$ & $\begin{array}{l}6.30 \\
(0.02)^{* *}\end{array}$ & $\begin{array}{l}11.36 \\
(0.00)\end{array}$ & $\begin{array}{l}-1.04 \\
(0.62)\end{array}$ & $\begin{array}{l}4.87 \\
(0.00)\end{array}$ & $\begin{array}{l}4.57 \\
(0.24)\end{array}$ \\
\hline
\end{tabular}

a 'GS3 Minor' refers to samples that consist of subjects as minor ethnicities in GS3.

b P-values in parentheses. ${ }^{*}$ coefficient is significantly different from zero at 0.10 level. ${ }^{* *}$ coefficient is significantly different from zero at 0.05 level. ${ }^{* * *}$ coefficient is significantly different from zero at 0.01 level.

Table 5: Results of the factor analysis of social survey

\begin{tabular}{lllll}
\hline Factor & Eigenvalue of Factor1 & \multicolumn{2}{l}{ Mean Score of Factor 1 } \\
& & Zang & Bouyei & Han \\
\hline PC & 2.06 & 0.07 & -0.22 & 0.14 \\
OR & 1.84 & -0.06 & -0.11 & 0.17 \\
RL & 4.68 & 0.84 & -0.25 & -0.59 \\
MI & 1.51 & -0.17 & -0.13 & 0.27 \\
CP & 2.32 & 0.46 & -0.11 & -0.30 \\
\hline
\end{tabular}

Table 6: Ordinary least squares regression result for contribution.

Independent Dependent Variable: Contribution

Variable Regression Models

Model 1

Model 2

Model 3

(Ethnic affiliation (Ethnic affiliation + (Ethnic

only ) Culture ) Culture 


\begin{tabular}{|c|c|c|c|c|}
\hline & & & & + Group structure) \\
\hline \multirow[t]{2}{*}{$\mathrm{EA} \times \mathrm{RL}$} & $\mathrm{EA}^{2} \times \mathrm{RL}$ & & $-0.41(0.65)$ & $-0.41(0.64)$ \\
\hline & $\mathrm{EA}^{3} \times \mathrm{RL}$ & & $-2.86(0.00)^{* * *}$ & $-2.86(0.00)^{* * *}$ \\
\hline \multirow[t]{2}{*}{$\mathrm{EA} \times \mathrm{MI}$} & $\mathrm{EA}^{2} \times \mathrm{MI}$ & & $0.09(0.87)$ & $0.09(0.87)$ \\
\hline & $\mathrm{EA}^{3} \times \mathrm{MI}$ & & $2.07(0.00)^{* * *}$ & $2.07(0.00)^{* * *}$ \\
\hline \multirow[t]{2}{*}{$\mathrm{EA} \times \mathrm{CP}$} & $\mathrm{EA}^{2} \times \mathrm{CP}$ & & $0.15(0.80)$ & $0.15(0.80)$ \\
\hline & $\mathrm{EA}^{3} \times \mathrm{CP}$ & & $-0.77(0.06)^{*}$ & $-0.77(0.06)^{*}$ \\
\hline RL & & & $1.52(0.00)^{* * *}$ & $1.52(0.00)^{* * *}$ \\
\hline MI & & & $-0.93(0.04)^{* *}$ & $-0.93(0.04)^{* *}$ \\
\hline $\mathrm{CP}$ & & & $1.28(0.00)^{* * *}$ & $1.28(0.00)^{* * *}$ \\
\hline \multirow[t]{2}{*}{ EA } & $\mathrm{EA}^{2}$ & $-1.16(0.00)^{* * *}$ & $-0.42(0.00)^{* * *}$ & $1.04(0.00)^{* * *}$ \\
\hline & $\mathrm{EA}^{3}$ & $-1.10(0.02)^{* *}$ & $-0.35(0.04)^{* *}$ & $0.77(0.07)^{*}$ \\
\hline MJ & & $-3.57(0.00)^{* * *}$ & $-2.37(0.00)^{* * *}$ & $-2.37(0.00)^{* * *}$ \\
\hline GD & & $1.97(0.00)^{* * *}$ & $2.38(0.00)^{* * *}$ & $2.38(0.00)^{* * *}$ \\
\hline EP & & $0.0004(0.46)$ & $-0.00005(0.93)$ & $-0.00005(0.93)$ \\
\hline EY & & $-0.08(0.23)$ & $-0.05(0.48)$ & $-0.05(0.48)$ \\
\hline \multirow[t]{2}{*}{ GS } & $\mathrm{GS}^{2}$ & & & $0.41(0.69)$ \\
\hline & $\mathrm{GS}^{3}$ & & & $0.31(0.76)$ \\
\hline \multirow[t]{4}{*}{$\mathrm{EA} \times \mathrm{GS}$} & $\mathrm{EA}^{2} \times \mathrm{GS}^{2}$ & & & $3.16(0.02)^{* *}$ \\
\hline & $\mathrm{EA}^{3} \times \mathrm{GS}^{2}$ & & & $-2.62(0.06)^{*}$ \\
\hline & $\mathrm{EA}^{2} \times \mathrm{GS}^{3}$ & & & $-1.60(0.26)$ \\
\hline & $\mathrm{EA}^{3} \times \mathrm{GS}^{3}$ & & & $-3.69(0.00)^{* * *}$ \\
\hline Constant & & $17.26(0.00)^{* * *}$ & $15.16(0.00)^{* * *}$ & $14.92(0.00)^{* * *}$ \\
\hline
\end{tabular}

a ' $E A^{\prime}$ is a dummy variable and ethnic Zang is defined as a reference, ' $E A^{2 '}$ and ' $E A^{3 \text { ' }}$ refer to the ethnic Bouyei and Han, respectively.

b ' $G S$ ' is a dummy variable and the group structure $G S 1$ are defined as a reference, ' $G S^{2}$ ' and ' $G S^{3}$ ' refer to the group structures, GS2 and GS3.

${ }^{\mathrm{c}}$ we classify all the majors as two categories, art and science. Thus, ' $M J$ ' is a dummy variable and the majors belonging to art are defined as the reference.

$\mathrm{d}$ ' $G D$ ' is a dummy variable and male is defined as the reference.

e P-values in parentheses. ${ }^{*}$ the coefficient is significantly different from zero at the 0.10 level. ${ }^{* *}$ the coefficient is significantly different from zero at the 0.05 level. ${ }^{* *}$ the coefficient is significantly different from zero at the 0.01 level.

Fig 1: Trends of contributions to group account over 10 rounds

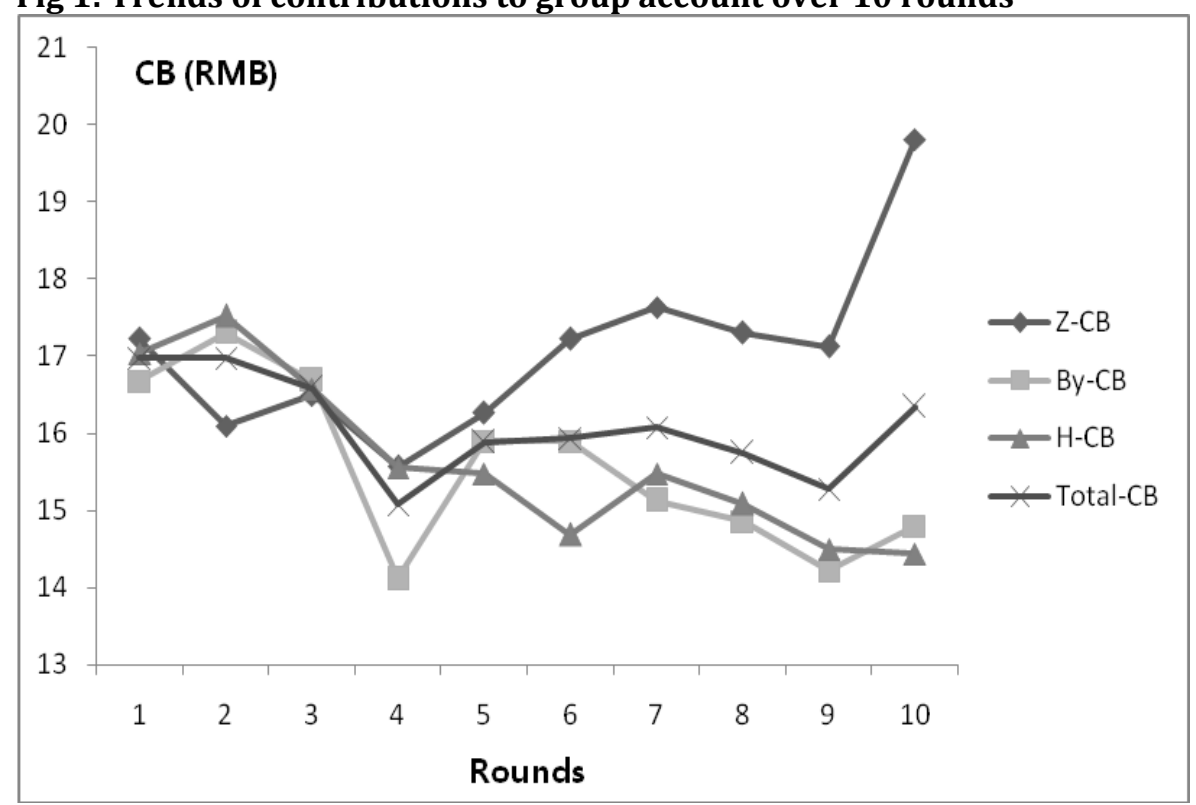


Fig 2: Trends of guesses over 10 rounds

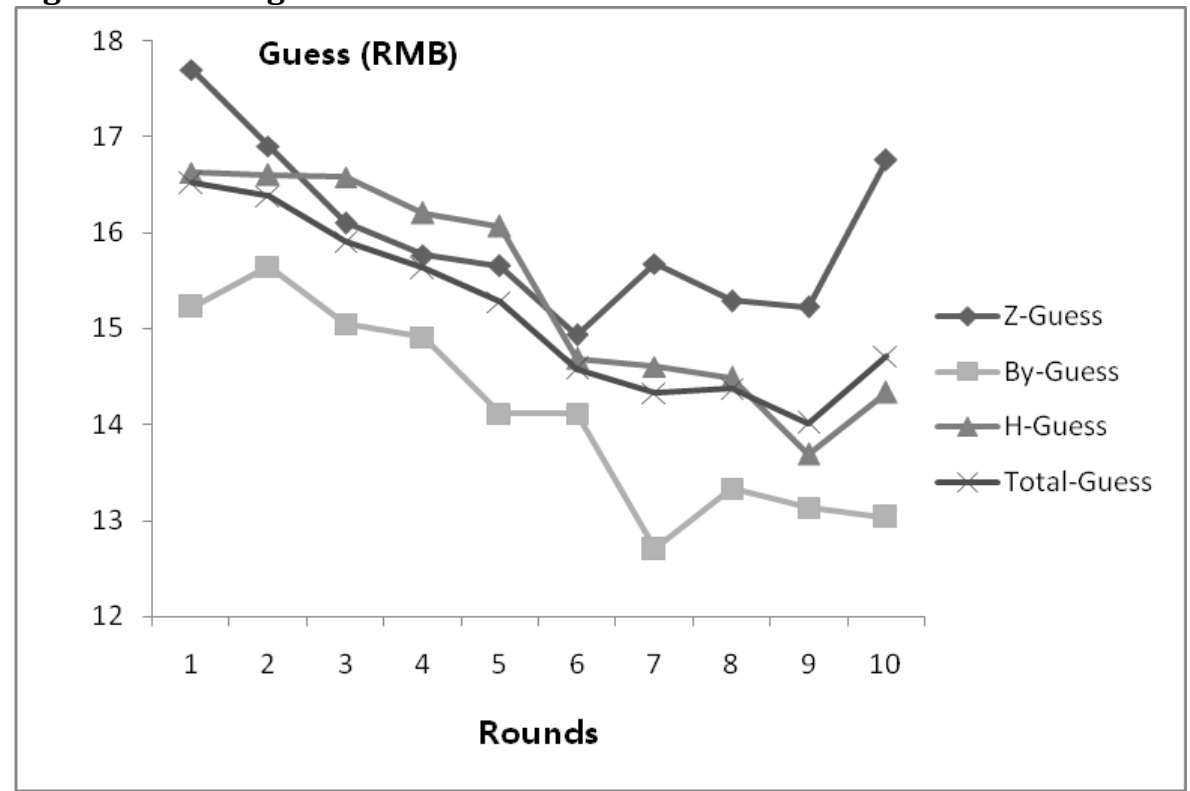

Appendix A

Prosocial Preference Survey

\begin{tabular}{|c|c|c|}
\hline Part A & Participation & \\
\hline & $\begin{array}{l}\text { Answer for each organization } \\
\text { and each activity } \\
2=\text { Inactive; } 3=\text { No): }\end{array}$ & $\begin{array}{l}\text { (a1) Church or religious organization: } \\
\text { (a2) Sport or recreational organization: } \\
\text { (a3) Art, music or educational organization: } \\
\text { (a4) Environmental organization: } \\
\text { (a5) Petition signing: } \\
\text { (a6) Boycotts: }\end{array}$ \\
\hline Part B & Outgroup Rejection & \\
\hline & $\begin{array}{l}\text { Do you mind if you have these } \\
\text { types of people as neighbors? } \\
\text { (1=I don't mind; } 2=\text { I don't } \\
\text { know; } 3=\text { Prefer not) }\end{array}$ & $\begin{array}{l}\text { (b1) Criminals: } \\
\text { (b2) Heavy drinkers: } \\
\text { (b3) Immigrants/foreign workers: } \\
\text { (b4) People who have AIDS: } \\
\text { (b5) Drug addicts: } \\
\text { (b6) Homosexuals: } \\
\text { (b7) People significantly different in social } \\
\text { status: } \\
\text { (b8) People significantly different in } \\
\text { wealth: }\end{array}$ \\
\hline Part C & Religion & \\
\hline & 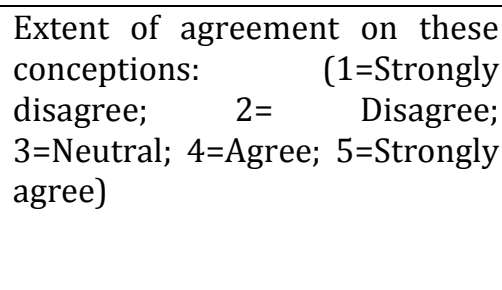 & $\begin{array}{l}\text { (c1) Belief in absoluteness of good and evil: } \\
\text { (c2) Belief in necessity of religious } \\
\text { upbringing: } \\
\text { (c3) Belong to a religious denomination: } \\
\text { (c4) Belief in god: } \\
\text { (c5) Belief in life after death: } \\
\text { (c6) Belief in soul: }\end{array}$ \\
\hline
\end{tabular}


(c7) Belief in heaven and hell:

(c8) Belief in importance of religion in life:

(c9) Belief in necessity of religion for human:

(c10) Deriving comfort and strength from religion:

\begin{tabular}{lll}
\hline Part D & Market Interaction & \\
\hline & $\begin{array}{l}\text { What proportions of these } \\
\text { necessities are purchased from }\end{array}$ & (d1) Clothing; \\
markets (0\% indicates the & (d3) Veogetables \\
necessity is self-sufficient, while & \\
$100 \%$ is totally purchased from & \\
market) & Centralization of Power & (e1) Significant economic affairs: \\
\hline Part $\boldsymbol{E}$ & Has some family member who & (e2) Children's education: \\
makes decisions of these home & (e3) Children's marriage: \\
affairs alone according to & \\
his/her family status (1= has; & \\
$0=$ has not)
\end{tabular}

Appendix B

\section{Experimental Instruction}

The instructions were read aloud by an experimenter as the students followed along on their computer screens.

This is an experiment, funded by a research foundation to study decision making. The instructions are simple. If you follow them carefully, you may earn a considerable amount of money which will be paid to you in cash at the end of experiment and the amount you earn will depend on you and other's decisions. Please make sure you understand the decision process and remember any communication is forbidden.

\section{Group}

You are about to participate experiment of a group decision-making that consists of three sessions, and every session includes 10 rounds, in other words, you will complete 30 rounds. During each round, you will be placed in a group with other four participants (a group of five). You will not know the identities of the other four members of your group in any given decision round, nor will you be told their identities after the experiment is over. At the beginning of each round, groups will be randomly assigned that you have no chance to meet the same person in any other round, i.e., group composition will be randomly changed from round to round. Moreover, you will not know additional information that we will not provide during the whole process.

\section{Earnings}

You will receive an initial endowment of 50 token (1 token=1RMB (0.16US\$)) in each round and have to decide on the allocation of your endowment between a private and public good. Each token placed in private one earns one token back while each token placed to public good earn 0.5 times token to each member of group. Your payoff will be determined as:

\section{(amount in personal account) $+(0.5)$ (total in group account)}

In addition to, you will be asked to guess the mean group contribution after decisionmaking in allocation in each round. Your payoff from guessing will be determined as follows (in $\mathrm{RMB})$ :

\section{$\left(\frac{1}{400}\right) \times(100-\mid \text { your guess - the actual average group contribution } \mid)^{2}$}

However, the calculation may be kind of complicated, note that the closer your guess is to the average group contribution, the higher is your payoff. Your total payoff in each round includes the payoff from the group decision as well as from guessing. At the end of the 
experiment, your earning is the average total payoff in 30 rounds. In each round, you will allowed to have 2 minutes to make decision, and if it is not enough, please let us know and more minutes will be allowed.

\section{Scenarios}

You belong to a different ethnicity. The experiment includes three sessions and each session corresponds to a single scenario. The scenario in the first session is that all of you are randomly divided into several groups and have to be aware that you play in a group probably with participants from different ethnicities. In the second session, you play in a group in which all the other participants belong to the ethnicity of your own. At the beginning of each round in third session, we will randomly select several participants. If you are selected, you will play in a group with other four participants belong to an ethnicity different from yours, and if not, you will play in a group with four other participants, only one of whom belongs to a different ethnicity from yours.

There will be some key questions which test whether you are familiar with the experiment institution. Our experimenters will check your answers and rectify the wrong ones with explanation, and if you have any more questions, please ask them before the experiment begins. GOOD LUCK! 